\title{
Prevalence of Obesity and Metabolic Syndrome in Children with Type 1 Diabetes: A Comparative Assessment Based on Criteria Established by the International Diabetes Federation, World Health Organisation and National Cholesterol Education Program
}

\author{
(1) Özlem Yayıcı Köken¹, (1) Cengiz Kara22, (1) Gülay Can Yılmaz³, (1) Hasan Murat Aydın4 \\ 1 University of Health Sciences Turkey, Dr. Sami Ulus Training and Research Hospital, Clinic of Pediatric Neurology, Ankara, Turkey \\ 2istinye University Faculty of Medicine, Department of Pediatrics, Istanbul, Turkey \\ ${ }^{3}$ Mardin State Hospital, Clinic of Pediatric Endocrinology, Mardin, Turkey \\ ${ }^{4}$ Ondokuz Mayıs University Faculty of Medicine, Department of Pediatric Endocrinology, Samsun, Turkey
}

What is already known on this topic?

Some studies have reported the prevalence of obesity and metabolic syndrome (MetS) in pediatric patients with type 1 diabetes (T1D). There are no such data from Turkey. In T1D patients diagnosis of MetS at early ages is critical to manage and prevent macrovascular complications. Nevertheless, identifying the presence of MetS in T1D is difficult and it is not clear which criteria are most suitable for accurate identification.

What this study adds?

The prevalence of obesity and MetS in children with T1D in our region is reported. MetS prevalence was $10.5 \%, 8.5 \%$ and $13.5 \%$ according to International Diabetes Federation (IDF), World Health Organisation (WHO) and National Cholesterol Education Program (NCEP) criteria, respectively. Also, this study comparatively assesses the widely accepted and used diagnostic criteria for MetS established by IDF, WHO and NCEP. Using IDF criteria seems more suitable because obesity is a prerequisite and they include accepted criteria for childhood.

\section{Abstract}

Objective: To determine the prevalence of obesity and metabolic syndrome (MetS) in children and adolescents with type 1 diabetes (T1D) and to compare the widely accepted and used diagnostic criteria for MetS established by the International Diabetes Federation (IDF), World Health Organisation (WHO) and National Cholesterol Education Program-Adult Treatment Panel III (NCEP-ATPIII).

Methods: We conducted a descriptive, cross sectional study including T1D patients between 8-18 years of age. The three sets of criteria were used to determine the prevalence of MetS and findings compared. Risk factors related to MetS were extracted from hospital records. Results: The study included 200 patients with T1D (52\% boys). Of these, $18 \%(n=36)$ were overweight/obese (body mass index percentile $\geq 85 \%$ ). MetS prevalence was $10.5 \%, 8.5 \%$ and $13.5 \%$ according to IDF, WHO and NCEP criteria, respectively. There were no statistically significant differences in age, gender, family history of T1D and T2D, pubertal stage, duration of diabetes, hemoglobin A1c levels and daily insulin doses between patients with or without MetS. In the overweight or obese T1D patients, the prevalence of MetS was $44.4 \%, 38.8 \%$ and $44.4 \%$ according to IDF, WHO and NCEP-ATPIII criteria, respectively.

Conclusion: Obesity prevalence in the T1D cohort was similar to that of the healthy population of the same age. Prevalence of MetS was higher in children and adolescents with T1D compared to the obese population in Turkey. The WHO criteria include microvascular complications which are rare in childhood and the NCEP criteria do not include a primary criterion while diagnosing non-obese patients according to waist circumference as MetS because the existence of diabetes is considered as a direct criterion. Our study suggests that IDF criteria which allows the diagnosis of MetS with obesity and have accepted criteria for the childhood are more suitable for the diagnosis of MetS in children and adolescents with T1D.

Keywords: Type 1 diabetes, metabolic syndrome, double diabetes, prevalence

Address for Correspondence: Özlem Yayı1 Köken MD, University of Health Sciences Turkey, Dr. Sami Ulus Training and Research Hospital, Department of Pediatric Neurology, Ankara, Turkey

Phone: + 905307624200 E-mail: drozlemkoken@gmail.com ORCID: orcid.org/0000-0003-2112-8284

Presented in: Preliminary data from this study were presented in poster form at the European Society of Pediatric Endocrinology Congress, Barcelona/Spain, 01-03 October, 2014.

${ }^{\circ}$ Copyright 2020 by Turkish Pediatric Endocrinology and Diabetes Society

The Journal of Clinical Research in Pediatric Endocrinology published by Galenos Publishing House.
Conflict of interest: None declared Received: 09.04.2019 Accepted: 16.08.2019 


\section{Introduction}

Type 1 diabetes (T1D) is a chronic disease characterized by absolute insulin deficiency due to immune-mediated destruction of pancreas beta cells. T1D has been associated with a leaner phenotype in the past. However, the number of obese patients with T1D is increasing, mirroring the global increase in obesity prevalence $(1,2)$. Metabolic syndrome (MetS), also called insulin resistance syndrome, comprises a cluster of diagnostic criteria including abdominal obesity, type 2 diabetes (T2D) and cardiovascular risk factors such as hypertension, dyslipidemia and nephropathy (3). Determining the frequency of MetS in patients with T1D requires the determination of coexisting obesity, hypertension and, dyslipidemia in these patients. Yet, studies in pediatric T1D patients to determine the prevalence of obesity and MetS are scarce.

In the T1D population, while the incidence of microvascular complications is decreasing owing to intensive diabetes management, macrovascular complications are now more commonly seen, a finding considered to be associated with the increasing incidence of obesity and MetS $(4,5,6,7,8)$. This has led to the realisation that diagnosis of MetS and obesity is essential if continued improvements in the quality and duration of life in children and adolescents with T1D is to be achieved. For the diagnosis of MetS in childhood and adolescence, the International Diabetes Federation (IDF) criteria are globally accepted. The World Health Organization (WHO) and the National Cholesterol Education ProgramAdult Treatment Panel III (NCEP-ATPIII) criteria used for the diagnosis of MetS in the adult population can also be used for children and adolescents, with some modifications. The aim of this study was to determine the prevalence of obesity and MetS in a large cohort of children and adolescents with $\mathrm{T} 1 \mathrm{D}$, and to compare widely accepted and used criteria for the diagnosis of MetS.

Ethics committee approval was received for this study from the Local Ethics Committee of the Faculty of Medicine, Samsun Ondokuz Mayis University (2014-354).

\section{Patients and Data Documentation}

A descriptive, cross sectional study was conducted, comprising a total of 200 T1D patients between 8-18 years of age who were followed up for at least six months. Clinical and laboratory data were obtained from the patients' medical records, including age, sex, anthropometric measurements, duration of diabetes, daily insulin dose (IU), degree of metabolic control based on mean annual hemoglobin A1c (HbA1c) values, comorbidities and treatments. History of T1D and/or T2D in first- and second-degree relatives was recorded. Laboratory results were collected which included HbA1c, total cholesterol, high density lipoprotein (HDL), low density lipoprotein (LDL) and triglyceride concentrations. Average IU per kg of body weight was calculated for the intensive insulin treatment group. Briefly, the total IU over three randomly selected days from the previous month was collected and mean daily dose was divided by body weight. The patients were evaluated for complications of diabetes and accompanying diseases. Existence of hypertension, prehypertension, microalbuminuria, retinopathy and neuropathy in addition to thyroid and coeliac disease were recorded. Patients who had other types of diabetes including T2D, maturity onset diabetes of the young and secondary diabetes were excluded from the study.

Height, weight and waist circumference (WC) were measured and body mass index (BMI) was calculated. Overweight and obesity were defined as a BMI $\geq 85^{\text {th }}$ and $\geq 95^{\text {th }}$ percentile, respectively (9).

The existence of hypertension was defined as a positive history of antihypertensive medicine or average blood pressure measurements above the $95^{\text {th }}$ percentile of Turkish pediatric age measurements determined by Tümer et al (10). Values between 90 and $95^{\text {th }}$ percentile were accepted as prehypertension while values below the $90^{\text {th }}$ percentile were accepted as normal. The amount of albumin measured in appropriately collected 24-hour urine samples was used to determine the existence of nephropathy. Albumin less than $30 \mathrm{mg}$ in 24 hours was considered negative and more than $30 \mathrm{mg}$ was considered positive for albuminuria. The existence of pathologic changes indicating retinopathy in ophthalmoscopy were recorded. The patients were questioned for coeliac disease and the scans were completed using laboratory tests when necessary.

Total daily insulin dosage for the last three months was obtained by randomly selecting three days from the patient records. Mean daily dose (IU/kg) was calculated by dividing total daily IU to patient weight (kg).

In order to establish the degree of metabolic control, mean HbA1c level, measured over the past year, was calculated. The patients were divided into three metabolic control groups based on mean annual HbA1 c: good, HbA1c $<7.5 \%$; moderate, HbA1c 7.5-9\%, and poor control, HbA1c >9\% (1).

The patient groups whose anthropologic and clinical data were recorded at first presentation, the third month of follow-up and the last routine clinic visit consisted mainly of patients who had ketoacidosis at presentation and patients who had just begun treatment. For this reason, data obtained after the onset of disease and at the third month of 
treatment were accepted as baseline values. The evaluation at the last routine clinic visit was deemed to represent outcomes under treatment.

WHO and NCEP-ATPIII diagnostic criteria were applied to the study cohort to determine the prevalence of MetS in addition to the IDF MetS criteria (2005) for children and adolescents. WHO defines MetS as glucose intolerance, impaired glucose tolerance or diabetes mellitus, and/or insulin resistance, along with two or more of the following: high blood pressure $(\geq 140 / 90$ $\mathrm{mmHg}$ ); hypertriglyceridemia ( $\geq 150 \mathrm{mg} / \mathrm{dL})$; and/or low HDL cholesterol $(<35 \mathrm{mg} / \mathrm{dL}$ in men and $<39 \mathrm{mg} / \mathrm{dL}$ in women); central obesity (waist/hip ratio $>0.9$ in men and $>0.85$ in women); and/or a BMI $>30 \mathrm{~kg} / \mathrm{m}^{2}$ and microalbuminuria (urinary albumin excretion rate $\geq 20 \mu \mathrm{g} /$ min or albumin/creatine ratio $\geq 30 \mu \mathrm{g} / \mathrm{mg}$ ) (11). According to the NCEP-ATPIII definition, a subject has MetS if they meet three or more of the following criteria: abdominal obesity ( $W C \geq 102 \mathrm{~cm}$ in men and $\geq 88 \mathrm{~cm}$ in women); hypertriglyceridemia ( $\geq 150 \mathrm{mg} / \mathrm{dL}$ ); low HDL cholesterol ( $<40 \mathrm{mg} / \mathrm{dL}$ in men and $<50 \mathrm{mg} / \mathrm{dL}$ in women); high blood pressure ( $>130 / 85 \mathrm{mmHg}$ ); and/or high fasting glucose (>110 mg/dL) (12). Children over eight years of age were eligible for the study because there were welldefined criteria to diagnose MetS in children aged six to 10 years and above 10 years (13). According to the IDF definition of MetS in children a subject has MetS if he or she is between 6 to 10 years of age and has obesity defined as having a $W C>90^{\text {th }}$ percentile. If the age is between 10 to 16 years, a subject has MetS if he or she has a WC value $>90^{\text {th }}$ percentile (or adult cut-off, if lower) and has two or more of the following criteria: hypertriglyceridemia ( $\geq 150 \mathrm{mg} / \mathrm{dL})$; low HDL cholesterol ( $<40 \mathrm{mg} / \mathrm{dL}$ ); high blood pressure percentile for age, sex and height; and/or raised fasting glucose (>100 mg/dL). Since WHO and NCEP-ATPIII criteria were formulated for adults, for the purposes of this study these criteria were modified for use in our study cohort by applying pediatric percentiles All children with T1D were assumed to have impairment of glucose tolerance and fasting high blood sugar. Impaired glucose tolerance, impaired fasting glycemia or existence of $\mathrm{T} 2 \mathrm{D}$, which are part of the mentioned criteria were accepted as positive for our T1D patient group. Patients were examined for the existence of either of the two remaining criteria. Dyslipidemia was accepted as a HDL concentration $<50 \mathrm{mg} / \mathrm{dL}$ and triglyceride $>150 \mathrm{mg} / \mathrm{dL}$. Pediatric percentiles were used for estimation of hypertension, WC and BMI (9). Patients with MetS according to the IDF criteria were compared in terms of demographic and clinical data.

\section{Statistical Analysis}

Data analyses were performed by using SPSS for Windows, version 22.0 (SPSS Inc., Chicago, IL, United States). Whether the distribution of continuous variables were normal or not was determined by Kolmogorov-Smirnov test. Levene test was used for the evaluation of homogeneity of variances. Unless specified otherwise, continuous data were described as mean \pm standard deviation (SD) for normal distributions, and median (range) for skewed distributions. Categorical data were described as number of cases (\%).

Statistical analysis differences in normally distributed variables between two independent groups were compared by Student's t-test, Mann-Whitney U test were applied for comparisons of the not normally distributed data. While the differences in normally distributed variables among more than two independent groups were analyzed by oneway ANOVA, otherwise, Kruskal-Wallis test was applied for comparisons of the not normally data. When the $p$ value from one-way ANOVA or Kruskal-Wallis test statistics were statistically significant post-hoc LSD or Conover's nonparametric multiple comparison test were used to know which group differ from which others.

\section{Results}

The study group consisted of 200 T1D patients with a mean age of $13.8 \pm 2.8$ years, duration of diabetes $4.6 \pm 3.3$ years. More than half $(52 \%)$ of the patients were male and the majority (87\%) pubertal. Mean HbA1c was $8.40 \pm 1.63 \%$ and mean IU was $0.87 \pm 0.26 \mathrm{U} /$ day. In the family history, T1D and T2D were present in $17.5 \%$ and $44 \%$ of the patients, respectively. Only three patients were using an insulin pump, and all the remaining patients $(n=197)$ were on multiple insulin injections. Metabolic control (mean annual $\mathrm{HbA} 1 \mathrm{c}$ ) across the whole cohort was good in $26.5 \%$, moderate in $37 \%$ and poor in $36.5 \%$. Of the 200 patients with T1D, 19 (9.5\%) were overweight and $17(8.5 \%)$ were obese.

Prevalence of MetS in the whole study cohort was $10.5 \%$, $8.5 \%$ and $13.5 \%$ according to IDF, WHO and NCEP-ATPIII criteria, respectively. Figure 1 shows a Venn diagram of the numbers of patients with MetS diagnosis according to different diagnostic criteria for whole group. However, in the 36 overweight/obese T1D patients, the prevalence of MetS was $44.4 \%, 38.8 \%$ and $44.4 \%$ according to IDF, WHO and NCEP-ATPIII criteria, respectively.

Table 1 depicts the clinical characteristics of MetS positive versus negative T1D patients according to IDF criteria. There were no statistically significant differences in age, gender, 
family history of T1D, pubertal stage, duration of diabetes, HbA1c levels and daily IU between patients with or without MetS but the difference was significant concerning family history of T2D and clinical and laboratory components of MetS. LDL-cholesterol and triglyceride concentrations were significantly elevated in patients with MetS $(p<0.001)$. When demographic and clinical data of patients with and without MetS according to WHO and NCEP-ATPII criteria were evaluated, similar results to IDF criteria were obtained (data not shown).
As shown in Table 2, BMI-SD score (SDS) values of all patients increased during intense insulin treatment following diagnosis according to the IDF, WHO and NCEPATPIII criteria. The BMI-SDS values of the group diagnosed with MetS according to IDF, WHO and NCEP-ATPIII criteria, were significantly greater than the non-MetS group in all three evaluations. All cases diagnosed as MetS according to all three sets of criteria had BMI values above the $50^{\text {th }}$ percentile at the diagnosis of T1D.

Table 1. Comparison of the demographic and clinical findings of type 1 diabetes patients with and without metabolic syndrome according to International Diabetes Federation criteria (10)

\begin{tabular}{|c|c|c|c|}
\hline $\begin{array}{l}\text { Characteristics } \\
\text { T1D }(n=200)\end{array}$ & $\begin{array}{l}\text { MetS positive } \\
\mathrm{n}=21(10.5 \%)\end{array}$ & $\begin{array}{l}\text { MetS negative } \\
\mathrm{n}=179(89.5 \%)\end{array}$ & $\mathrm{p}$ value \\
\hline Gender (male) (n, \%) & $10(47.6)$ & $94(52.5)$ & 0.671 \\
\hline Age (years) (mean \pm SD) & $13.7 \pm 3.3$ & $13.8 \pm 2.8$ & 0.995 \\
\hline \multicolumn{4}{|l|}{ Pubertal status (n, \%) } \\
\hline Prepubertal & $4(19)$ & $22(12.3)$ & 0.488 \\
\hline Postpubertal & $17(81)$ & $157(87.5)$ & \\
\hline \multicolumn{4}{|l|}{ Family history (n, \%) } \\
\hline T1D & $3(14.3)$ & $32(17.9)$ & 1 \\
\hline T2D & $13(61.9)$ & $75(41.8)$ & 1 \\
\hline Duration of diabetes (mo) & $57.3 \pm 45.8$ & $54.9 \pm 39.2$ & 0.949 \\
\hline Waist circumference $(\mathrm{cm})($ mean $\pm \mathrm{SD})$ & $82.9 \pm 10.8$ & $67.9 \pm 7.7$ & $<0.001$ \\
\hline Waist circumference SDS (mean \pm SD) & $2.2 \pm 0.6$ & $0.3 \pm 0.97$ & $<0.001$ \\
\hline Insulin dose (U/kg) (mean $\pm \mathrm{SD})$ & $0.9 \pm 0.2$ & $0.9 \pm 0.3$ & 0.932 \\
\hline \multicolumn{4}{|c|}{ Status of metabolic control (HbA1c \%) (n, \%) } \\
\hline Good $(\leq 7.5)$ & $4(19)$ & $49(27.4)$ & \\
\hline Moderate (7.5-9.0) & $8(38.1)$ & 66 (36.9) & 0.684 \\
\hline Poor $(\geq 9.0)$ & $9(42.9)$ & $64(35.8)$ & \\
\hline Existence of acanthosis (n, \%) & $5(23.8)$ & $6(3.4)$ & 0.002 \\
\hline \multicolumn{4}{|l|}{ Comorbidities (n, \%) } \\
\hline Prehypertension & $2(9.5)$ & $5(2.8)$ & $<0.001$ \\
\hline Hypertension & $14(66.7)$ & $10(5.6)$ & $<0.001$ \\
\hline Dyslipidemia & $12(21.1)$ & $45(78.9)$ & 0.004 \\
\hline Microalbuminuria & - & $8(4.5)$ & 1.000 \\
\hline \multicolumn{4}{|l|}{ Existence of additional disease (n, \%) } \\
\hline Thyroid autoantibody positivity & $3(14.3)$ & $25(14)$ & 1.000 \\
\hline Thyroid disease & $1(4.8)$ & $19(10.6)$ & 0.701 \\
\hline Coeliac disease & - & $4(2.2)$ & 1.000 \\
\hline \multicolumn{4}{|l|}{ HbA1c levels (mean $\pm \mathrm{SD})$} \\
\hline Recent year & $8.8 \pm 1.4$ & $8.6 \pm 1.5$ & 0.374 \\
\hline At the most recent control & $8.6 \pm 1.5$ & $8.4 \pm 1.6$ & 0.439 \\
\hline \multicolumn{4}{|l|}{ Lipid profile (mean \pm SD) } \\
\hline Triglyceride (mg/dL) & $130.1 \pm 60.4$ & $85.2 \pm 42.0$ & $<0.001$ \\
\hline HDL cholesterol (mg/dL) & $55.4 \pm 15.4$ & $62.1 \pm 15.6$ & 0.050 \\
\hline LDL cholesterol (mg/dL) & $106.2 \pm 20.3$ & $77.0 \pm 24.7$ & $<0.001$ \\
\hline
\end{tabular}

IDF: International Diabetes Federation, MetS: metabolic syndrome, T1D: type 1 diabetes, T2D: type 2 diabetes, SD: standard deviation, SDS: SD score, HbA1 C: hemoglobin A1c, HDL: high density lipoprotein, LDL: low density lipoprotein 


\section{Discussion}

There is no data on the prevalence of obesity in children and adolescents with T1D in Turkey. In our study group, comprising 200 children with T1D between 8 and 18 years, total prevalence of overweight and obesity was found to be $18 \%$. The prevalence of overweight and obesity in schoolchildren and adolescents from different regions of our country has been reported in the range of 12.8-20.2\% $(14,15,16,17,18)$. Accordingly, the present study has shown that obesity prevalence of our T1D cohort was similar to that of the general population in Turkey. Studies from other

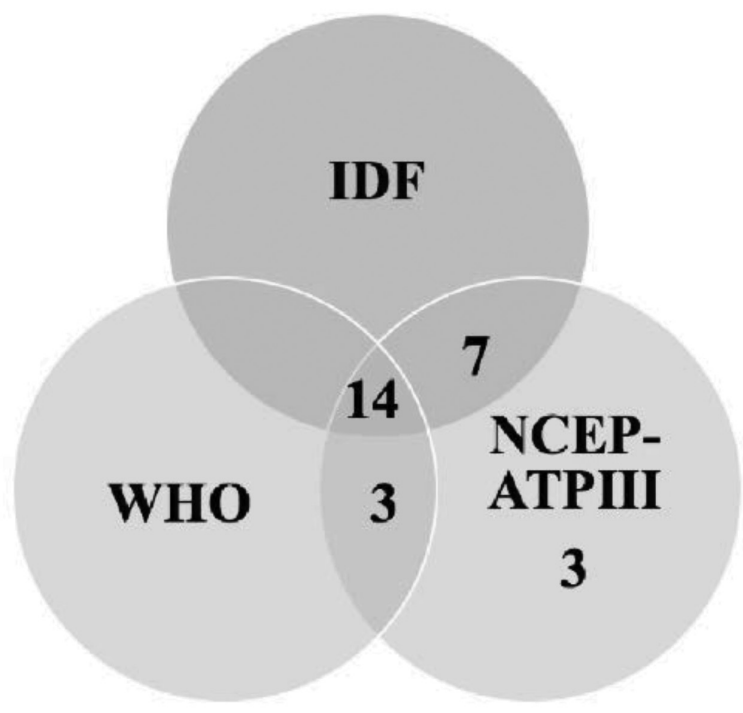

Figure 1. The numbers of patients with metabolic syndrome diagnosis based on different diagnostic criteria

IDF: International Diabetes Federation, WHO: World Health Organisation, NCEP-ATPIII: National Cholesterol Education ProgramAdult Treatment Panel III countries have indicated that the increased incidence of overweight and obesity in T1D population mirrors what happens in the general population $(19,20,21,22,23)$. Although the traditional belief is that patients with T1D are normal or thin, overweight and obesity figures in these patients have been found to increase in parallel with the normal population. Intense insulin therapy and weight gain due to the anabolizing and lipogenic effect of insulin are thought to be responsible for the increase. Additionally, the change in nutrition habits and shift to sedentary life style which are probably responsible for a global increase in overweight and obesity have also affected the young population with T1D. At present, T1D patients are more obese compared to the past, which has been associated with intense insulin treatment. The Epidemiology of Diabetes Interventions and Complications study revealed that the incidence of obesity in T1D patients has significantly increased due to widespread intense insulin treatment following Diabetes Control and Complications Trial $(23,24,25)$. Some authors indicated that being female was a risk factor for a higher BMI-SDS six years after diabetes onset (26). All of our patients had gained weight at the time of diagnosis, third month of follow up and the last visit. Since the patients probably lost weight before diagnosis, the BMI-SDS values at the third month follow up and the last visit were evaluated and a striking weight gain was present. This reflects the effect of intense insulin treatment. All the patients gained weight but weight gain was more pronounced in the MetS positive group. Another striking point is that the BMI and BMI-SDS values in the MetS positive group were significantly higher than the MetS negative group and this was present from diagnosis up until the study period.

Table 2. Changes in body mass index-standard deviation score values over time among metabolic syndrome positive and negative groups according to International Diabetes Federation, World Health Organisation and National Cholesterol Education Program-Adult Treatment Panel III criteria

\begin{tabular}{|c|c|c|c|c|}
\hline \multirow[t]{2}{*}{ Time } & \multirow[t]{2}{*}{ Criteria } & \multicolumn{2}{|l|}{ BMI-SDS } & \multirow[t]{2}{*}{$\mathrm{p}$ value } \\
\hline & & MetS $(+)$ & MetS (-) & \\
\hline \multirow{2}{*}{ At time of diagnosis } & IDF & $0.3 \pm 1.6$ & $-0.8 \pm 1.7$ & 0.004 \\
\hline & NCEP-ATPIII & $0.4 \pm 1.8$ & $-0.8 \pm 1.7$ & $<0.001$ \\
\hline At third month of follow up & IDF & $1.0 \pm 0.3$ & $-0.7 \pm 1.1$ & 0.003 \\
\hline \multirow{3}{*}{ During study period } & IDF & $1.3 \pm 0.8$ & $-0.1 \pm 1.1$ & $<0.001$ \\
\hline & WHO & $1.1 \pm 0.8$ & $-0.1 \pm 1.1$ & $<0.001$ \\
\hline & NCEP-ATPIII & $1.2 \pm 1.0$ & $-0.15 \pm 1.0$ & $<0.001$ \\
\hline
\end{tabular}

BMI-SDS: body mass index-standard deviation score, MetS: metabolic syndrome, IDF: International Diabetes Federation, WHO: World Health Organisation,

NCEP-ATPIII: National Cholesterol Education Program-Adult Treatment Panel III 
Data on MetS prevalence in patients with T1D is controversial. The prevalence of MetS was evaluated using three sets of recognized criteria and in 200 T1D children; it was $10.5 \%$ according to IDF, $8.5 \%$ according to WHO and $13.5 \%$ according to NCEP-ATPIII. Although there are no studies that report the prevalence of MetS in children and adolescents with T1D in Turkey, MetS seems to be more common in the T1D population when compared to the obese population. The results of the small number of studies comparing the prevalence of MetS in T1D children and adolescents vary between countries. In a study where 115 T1D patients between 5-16 years of age were investigated, MetS prevalence was found to be $13.2 \%$ according to IDF. The researchers found a significantly low incidence of MetS for that study population $(27,28)$. Pinhas-Hamiel et al $(20)$ reported a $7.1 \%$ prevalence of MetS in $326 \mathrm{~T} 1 \mathrm{D}$ patients whose median age was 18.5 years.

The prevalence of MetS in overweight and obese children and adolescents in Turkey has been reported to vary between 20\%-38\% according to WHO, IDF and NCEPATPIII criteria $(29,30,31)$. In our study, the incidence of MetS in overweight and obese patients was $41.7 \%$ according to IDF, $38.3 \%$ according to $\mathrm{WHO}$ and $47.2 \%$ according to NCEP-ATPIII criteria which is somewhat higher than has previously been reported but may simply reflect the secular trend in increasing prevalence of overweight and obesity.

Although it is widely accepted that it is necessary to diagnose MetS in the early stages of T1D, the main problem is the inadequacy of the criteria for the diagnosis of MetS in T1D patients. Use of the NCEP-ATPIII criteria resulted in the highest prevalence in our study (13.5\%) since NCEP-ATPIII allows diagnosis of MetS by any three positive out of five criteria, with no mandatory prerequisites. Since diabetes is accepted as positive, two out of the remaining four criteria are enough and these criteria are already present in patients diagnosed using IDF criteria. As such, the MetS positive group determined by NCEP-ATPIII includes both the IDF criteria group and the group which did not meet the WC criterion, that is they are not obese according to WC, but are positive for two other criteria. The WC of the group which meets NCEP-ATPIII criteria but not the IDF criteria is below $90^{\text {th }}$ percentile while the two criteria they met were any two of hypertriglyceridemia, low HDL or hypertension. Since there are no primary criteria in NCEPATPIII and it evaluates the WHO dyslipidemia criteria as two distinct criteria, it encompasses all cases diagnosed using WHO and IDF.

When the results of our study were evaluated according to IDF criteria, it was evident that the incidence of MetS was higher in the group where T1D was accompanied by overweight and obesity when compared to those who do not have T1D but are overweight or obese. The incidence of MetS is similar in overweight and obese individuals independent of T1D, according to WHO criteria. This discrepancy is caused by differences in definitions of MetS. Impaired glucose tolerance or T2D is a prerequisite for MetS in the WHO criteria, so it is understood that MetS prevalence will not change if the criteria is actualized as T1D. On the other hand, obesity as determined by WC is a prerequisite for MetS while impaired glucose tolerance and T2D are secondary criteria. Since this criterion is met by all patients in addition to obesity in our study population, which consisted of T1D patients, the ratio was found to be high.

On the other hand, insulin resistance and/or diabetes are mandatory primary criteria for the WHO definition and our T1 D patient group meet these criteria. The WHO criteria also include microalbuminuria, which has the highest sensitivity for MetS in adulthood. However, our study group, because of the patient age range, had the lowest prevalence for this criterion, since these complications had not yet occurred $(32,33,34)$. In the study group, there were 25 patients whose BMI was below the $95^{\text {th }}$ percentile while WC was above the $90^{\text {th }}$ percentile, which led to the identification of more MetS using IDF and NCEP-ATPIII in T1D. All patients who were diagnosed positive using the $\mathrm{WHO}$ criteria are found to also meet NCEP-ATPIII.

The WHO criteria include microvascular complications, which are rare in childhood, and the NCEP criteria do not include a primary criterion while diagnosing non-obese patients according to WC as MetS because the existence of diabetes is considered as a direct criterion. Due to these reasons, these criteria do not seem to be useful for the diagnosis of MetS in children and adolescents with T1D. Using IDF criteria seems more suitable because obesity is a prerequisite and they include accepted criteria for childhood $(11,12,13)$.

\section{Study Limitations}

Our study has several limitations and strengths. The main limitation is the absence of accepted clinical and laboratory criteria for the diagnosis of MetS in children and adolescents with T1D. Thus existing criteria had to be modified for a pediatric population in order to determine the prevalence. On the other hand, using and comparing three different modified criteria is a strength of our study. A further strength of this study lies in the accuracy of data, which adds to the available information concerning the prevalence of MetS in children and adolescents with T1D. 


\section{Conclusion}

Overweight and obesity prevalence of the group with T1D was similar to that of the population of the same age group in Turkey, but the prevalence of MetS was found to be higher than that of the general population. Except for the components of MetS, the other clinical and laboratory parameters were not helpful for prediction. It has been observed that all children and adolescents with T1D gained weight under intense insulin treatment. However, weight gain was more prominent in the MetS positive group. It is clear that appropriate modification of the criteria is required for the early detection of MetS in children and adolescents with T1D. This study suggests that IDF criteria are more suitable for the diagnosis of MetS in children and adolescents with T1D.

\section{Ethics}

Ethics Committee Approval: The Local Ethics Committee of Faculty of Medicine, Samsun Ondokuz Mayis University (approval number: 2014-354).

Informed Consent: Written informed consent was obtained from the parents of the patients who participated in this study.

Peer-review: Externally and internally peer-reviewed.

\section{Authorship Contributions}

Surgical and Medical Practices: Özlem Yayıcı Köken, Cengiz Kara, Gülay Can Yılmaz, Hasan Murat Aydın, Concept: Özlem Yayıcı Köken, Cengiz Kara, Gülay Can Yılmaz, Hasan Murat Aydın, Design: Özlem Yayıcı Köken, Cengiz Kara, Gülay Can Yılmaz, Hasan Murat Aydın, Data Collection or Processing: Özlem Yayıcı Köken, Cengiz Kara, Gülay Can Yılmaz, Hasan Murat Aydin, Analysis or Interpretation: Özlem Yayıcı Köken, Cengiz Kara, Gülay Can Yılmaz, Hasan Murat Aydın, Literature Search: Özlem Yayıcı Köken, Cengiz Kara, Gülay Can Yılmaz, Hasan Murat Aydın, Writing: Özlem Yayıcı Köken, Cengiz Kara, Gülay Can Yılmaz, Hasan Murat Aydin.

Conflict of Interest: No conflict of interest was declared by the authors.

Financial Disclosure: The authors declared that this study received no financial support.

\section{References}

1. Defronzo RA, Simonson D, Ferrannini E. Hepatic And Peripheral Insulin Resistance: A Common Feature Of Type 2 (Non-Insulin-Dependent) And Type 1 (Insulin-Dependent) Diabetes Mellitus. Diabetologia 1982;23:313-319.
2. Teupe B, Bergis K. Epidemiological Evidence For "Double Diabetes." Lancet 1991;337:361-362.

3. No authors listed. Standards of Medical Care in Diabetes-2016: Summary of Revisions. Diabetes Care 2017;40(Suppl 1):4-5.

4. Roglic G, Colhoun HM, Stevens LK, Lemkes HH, Manes C, Fuller JH. Parental History of Hypertension And Parental History of Diabetes and Microvascular Complications In Insulin-Dependent Diabetes Mellitus: The EURODIAB IDDM Complications Study. Diabet Med 1998;15:418-426.

5. Bikhazi AB, Azar ST, Birbari AE, El-Zein GN, Haddad GE, Haddad RE, Bitar KM. Characterization of Insulin-Resistance: Role of Receptor Alteration In Insulin dependent Diabetes Mellitus, Essential Hypertension And Cardiac Hypertrophy. Eur J Pharm Sci 2000;11:299. 306.

6. Heptulla RA, Stewart A, Enocksson S, Rife F, Ma TY, Sherwin RS, Tamborlane WV, Caprio S. In Situ Evidence That Peripheral Insulin Resistance In Adolescents With Poorly Controlled Type 1 Diabetes Is Associated With Impaired Suppression Of Lipolysis: A Microdialysis Study. Pediatr Res 2003;53:830-835.

7. Perseghin G, Lattuada G, Danna M, Sereni LP, Maffi P, De Cobelli F, Battezzati A, Secchi A, Del Maschio A, Luzi L. Insulin Resistance, Intramyocellular Lipid Content And Plasma Adiponectin In Patients With Type 1 Diabetes. Am J Physiol Endocrinol Metab 2003;285:11741181. Epub 2003 Aug 21

8. Sinha R, Dufour S, Petersen KF, LeBon V, Enoksson S, Ma YZ, Savoye M, Rothman DL, Shulman GI, Caprio S. Assessment Of Skeletal Muscle Triglyceride Content By $1 \mathrm{H}$ Nuclear Magnetic Reso-nance Spectroscopy In Lean And Obese Adolescents: Relationships To Insulin Sensiti-vity, Total Body Fat, And Central Adiposity. Diabetes 2002;51:1022-1027.

9. Neyzi O, Günöz H, Furman A, Bundak R, Gökçay G, Darendeliler F, Baş F. Türk Çocuklarında Vücut Ağırlığı, Boy Uzunluğu, Baş Çevresi Ve Vücut Kitle Indeksi Referans Değerleri. Çocuk Sağlığı Ve Hastalıkları Dergisi 2008;51:1-14

10. Tümer N, Yalçinkaya F, Ince E, Ekim M, Köse K, Cakar N, Kara N, Ozkaya N, Ensari C, Onder S. Blood pressure nomograms for children and adolescents in Turkey. Pediatr Nephrol. 1999;13:438-443.

11. Part 1: diagnosis and classification of diabetes mellitus. World Health Organization: Geneva, Switzerland; 1999. Last accessed on: 2011 Jun 03. World Health Organization. Definition, diagnosis and classification of diabetes mellitus and its complications: Report of a WHO Consultation.

12. Grundy SM, Cleeman JI, Daniels SR, Donato KA, Eckel RH, Franklin BA, Gordon DJ, Krauss RM, Savage PJ, Smith SC Jr, Spertus JA, Costa F; American Heart Association; National Heart, Lung, and Blood Institute. Diagnosis and management of the metabolic syndrome: an American Heart Association/National Heart, Lung, and Blood Institute Scientific Statement. Circulation 2005;112:2735-2752. Epub 2005 Sep 12

13. Zimmet P, Alberti G, Kaufman F, Tajima N, Silink M, Arslanian S, Wong G, Bennett P, Shaw J, Caprio S; International Diabetes Federation Task Force on Epidemiology and Prevention of Diabetes. The Metabolic Syndrome in children and adolescents. Lancet 2007;369:2059-2061.

14. Çelmeli G, Çürek Y, Arslan Gülten Z, Yardımsever M, Koyun M, Akçurin $\mathrm{S}$, Bircan I. Remarkable Increase in the Prevalence of Overweight and Obesity Among School Age Children in Antalya, Turkey, Between 2003 and 2015. J Clin Res Pediatr Endocrinol 2019;11:76-81. Epub 2018 Sep 25

15. Bereket A, Atay Z. Current Status Of Childhood Obesity And Its Associated Morbidities In Turkey. J Clin Res Pediatr Endocrinol 2012;4:1-7.

16. Kaya M, Sayan A, Birinci M, Yildiz M, Türkmen K. The Obesity Prevalence Among Students Between The Ages Of 5 And 19 In Kütahya. Turk J Med Sci 2014;44:10-15. 
17. Gökler ME, Buğrul N, Metintaş S, Kalyoncu C. Adolescent Obesity And Associated Cardiovascular Risk Factors Of Rural And Urban Life (Eskisehir, Turkey). Cent Eur J Public Health 2015;23:20-25.

18. Inanc BB. Metabolic Syndrome In School Children In Mardin, SouthEastern Of Turkey. Eurasian J Med 2014;46:156-163. Epub 2014 Aug 26

19. Krochik AG, Botto M, Bravo M, Hepner M, Frontroth JP, Miranda M, Mazza C. Association Between Insulin Resistance And Risk Of Complications In Children And Adolescents With Type 1 Diabetes. Diabetes Metab Syndr 2015;9:14-18. Epub 2014 Oct 18

20. Pinhas-Hamiel O, Levek-Motola N, Kaidar K, Boyko V, Tisch E, MazorAronovitch K, Graf-Barel C, Landau Z, Lerner-Geva L, Frumkin BenDavid R. Prevalence Of Overweight, Obesity And Metabolic Syndrome Components In Children, Adolescents And Young Adults With Type 1 Diabetes Mellitus. Diabetes Metab Res Rev 2015;31:76-84.

21. Sandhu N, Witmans MB, Lemay JF, Crawford S, Jadavji N, Pacaud D. Prevalence Of Overweight And Obesity In Children And Adolescents With Type 1 Diabetes Mellitus. J Pediatr Endocrinol Metab 2008;21:631640.

22. Polsky S, Ellis SL. Obesity, insulin resistance, and type 1 diabetes mellitus. Curr Opin Endocrinol Dibetes Obes 2015;22:277-282.

23. Luczyński W, Szypowska A, Bossowski A, Ramotowska A, Rećko P, Rembińska M, Tercjak M, Blecharczyk B, Lachowska U, Suchoń P, Wiśniewska K, Bernatowicz P, Głowińska-Olszewska B. Overweight, Obesity And Metabolic Syndrome In Children With Type 1 Diabetes Mellitus. Pediatr Endocrinol Diabetes Metab 2010;16:83-88.

24. Ferreira-Hermosillo A, Ramírez-Rentería C, Mendoza-Zubieta V, MolinaAyala MA. Utility Of The Waist-To-Height Ratio, Waist Circumference And Body Mass Index In The Screening Of Metabolic Syndrome In Adult Patients With Type 1 Diabetes Mellitus. Diabetol Metab Syndr $2014 ; 6: 32$.

25. Castro-Correia C, Santos-Silva R, Pinheiro M, Costa C, Fontoura M. Metabolic risk factors in adolescent girls with type 1 diabetes. J Pediatr Endocrinol Metab 2018;31:631-635.

26. De Vries L, Bar-niv M, Lebenthal Y, Tenenbaum A, Shalitin S, Lazar L, Cohen A, Phillip M. Changes in weight and BMI following the diagnosis of type 1 diabetes in children and adolescents. Acta Diabetol 2014;51:395-402.

27. De Keukelaere M, Fieuws S, Reynaert N, Vandoorne E, Kerckhove KV, Asscherickx W, Casteels K. Evolution of body mass index in children with type 1 diabetes mellitus. Eur J Pediatr 2018;177:1661-1666.

28. Cizmecioglu FM, Etiler N, Hamzaoglu O, Hatun S. Prevalence Of Metabolic Syndrome In Schoolchildren And Adolescents In Turkey: A Population-Based Study. J Pediatr Endocrinol Metab 2009;22:703-714.

29. l'Allemand-Jander D. Clinical diagnosis of metabolic and cardiovascular risks in overweight children: early development of chronic diseases in the obese child. Int J Obes (Lond) 2010;34(Suppl 2):32-36

30. Palomo Atance E, Giralt Muiña P, Ballester Herrera MJ, Ruiz Cano R, León Martín A, Giralt Muiña J. An Prevalence Of Obesity And Cardiovascular Risk Factors In A Group Of Paediatric Patients With Type 1 Diabetes. An Pediatr (Barc) 2013;78:382-388. Epub 2012 Dec 28

31. Sangun Ö, Dündar B, Köşker M, Pirgon Ö, Dündar N. Prevalence Of Metabolic Syndrome In Obese Children And Adolescents Using Three Different Criteria And Evaluation Of Risk Factors. J Clin Res Pediatr Endocrinol 2011;3:70-76. Epub 2011 Jun 8

32. Pambianco G, Costacou T, Orchard TJ. The Prediction Of Major Outcomes Of Type 1 Diabetes: A 12-Year Prospective Evaluation Of Three Separate Definitions Of The Metabolic Syndrome And Their Components And Estimated Glucose Disposal Rate: The Pittsburgh Epidemiology Of Diabetes Complications Study Experience. Diabetes Care 2007;30:1248-1254. Epub 2007 Feb 15.

33. Thorn LM, Forsblom C, Fagerudd J, Thomas MC, Pettersson-Fernholm K, Saraheimo $M$, Wadén J, Rönnback $M$, Rosengård-Bärlund $M$, Björkesten CG, Taskinen MR, Groop PH; FinnDiane Study Group. Metabolic Syndrome In Type 1 Diabetes Association With Diabetic Nephropathy And Glycemic Control (The Finndiane Study). Diabetes Care 2005;28:2019-2024.

34. Santos CE, Schrank Y, Kupfer R. Critical Analysis Of WHO, IDF And NCEP Criteria For Metabolic Syndrome Among Patients With Type 1 Diabetes Mellitus. Arq Bras Endocrinol Metabol 2009;53:1096-1102. 